\title{
A Dinâmica do Emprego e da Desigualdade na Renda do Trabalho nos Diferentes Setores da Indústria $G$ aúcha entre 1996 e $2005^{1}$.
}

\author{
Izete Pengo Bagolin* \\ Valter J osé Stulp** \\ Leonardo Amaral Scavoni***
}

Resumo: 0 objetivo deste artigo é entender as mudanças ocorridas na desigualdade dos rendimentos salariais dos trabalhadores dos diferentes setores da indústria gaúcha entre 1996 e 2005. Para isso, em relação a cada setor, é calculado o índice de Gini da distribuição dos rendimentos do salário. Posteriormente, a partir de regressões, busca-se identificar os fatores que explicam as desigualdades ocorridas. O s resultados dessa investigação mostram que entre 1996 e 2005 ocorreu redução na desigualdade dos rendimentos do trabalho no Rio Grande do Sul. Esta redução na desigualdade ocorreu ao longo de um período marcado por alterações e oscilações importantes na indústria e com um aumento do número de trabalhadores ocupados inferior ao crescimento da produção. Ou seja, ocorreu aumento na produtividade do trabalho e, ao mesmo tempo, ocorreu uma elevação do nível de escolaridade dos trabalhadores ocupados. No entanto, o que mais chama atenção é que a redução na desigualdade é consequência de um achatamento salarial e do aumento do número de trabalhadores ocupados em empregos de menor remuneração. Em outras palavras, os trabalhadores da indústria gaúcha acumularam capital humano, produzem mais e ganham menos.

Palavras-chave: Desigualdade da Renda dos Salários, Setores Industriais, Educação.

A bstract: This article analyses the changes that occurred from 1996 to 2005 in the distributions of the wages among the workers in different industrial sectors in the state of Rio Grande do Sul. The inequalitiesin the distributions were expressed through Gini indices. Statistical regressions were used to identify the variables responsible for the changes in these inequalities. The results show that from 1996 to 2005 occurred a reduction in the inequality of the industrial salary's income distribution in Rio Grande do Sul. But this reduction in the income

\footnotetext{
* Professora do PPGE/PUCRS. E-mail: izete.bagolin@pucrs.br.

** Professor do PPGE/PUCRS. E-mail: vstulp@ pucrs.br.

*** Graduando em Economia - PUCRS. E-mail: leonardoascavoni@ hotmail.com.

1 Este trabalho contou com o auxilio da FAPERGS, na forma de uma Bolsa de Iniciação Científica.
} 
inequality is due to a decrease in the average salary received by the workers and a great rise in the proportion of workers occupying positions with lower salaries. During this period the number of the State industrial workers increased at a lower rate than the value of its output, meaning that labor productivity raised. In the same period the educational level of the workersincreased. Thus, the State industrial workers accumulated human capital, increased their productivity, but their wages declined.

Keyw ords: Inequality in the Distribution of Salaries, Industrial Sectors, Educational Level.

J EL Classification: J 2, J 21

\section{Introdução}

Apesar do baixo crescimento e da crise que a economia do Rio Grande do Sul e, especialmente, o setor industrial vem enfrentando nos últimos anos, percebe-se que ocorreu um aumento da participação relativa do setor industrial no Valor Adicionado Bruto (VAB) estadual. Esta participação, em 1996, representava 36,6\% do valor total produzido e passou para $44,52 \%$ em 2005 . No entanto, utilizando-se a taxa de crescimento do VAB industrial, percebe-se que este, apesar de inconstante, apresentou crescimento superior ao PIB Gaúcho. No acumulado, no período 1996-2005, teve um crescimento de $29,24 \%$, o que equivale a uma média de crescimento anual de $2,9 \%$ a.a. Usando as variações percentuais anuais, tem-se que, em 1996, o crescimento do PIB foi de $0,5 \%$ e o do VAB industrial foi de $0,2 \%$. J á em 2005 , o PIB estadual apresentou uma taxa de crescimento negativa de $(-5,2 \%)$ e o VAB industrial decresceu em (- 4,8\%). A carta de Conjuntura no 15 da Fundação de Economia e Estatística mostra que além da queda do VAB industrial, em 2005, ocorreu uma redução de $(-6,1 \%)$ no pessoal ocupado no setor industrial Gaúcho. 0 período recente, inclusive, mostra que a indústria gaúcha apresentou trajetória divergente da indústria Nacional. Porém, no acumulado, o número de trabalhadores assalariados aumentou aproximadamente $27 \%$.

Partindo deste cenário de baixo crescimento permeado por períodos de crise da indústria gaúcha, o objetivo deste artigo é entender como e por quem a desigualdade dos rendimentos dos trabalhadores dos diferentes setores foi afetada entre 1996 e 2005. O Rio Grande do Sul, apesar de ser considerado um estado desenvolvido com Índice de Desenvolvimento Humano acima de 0,80, possui uma distribuição de renda desigual, com índice de Gini de 0,52 (IPEADATA, 2007).

Uma vez que a renda dos salários é parte importante da renda estadual e influencia diretamente a dinâmica econômica e o padrão 
de vida dos gaúchos, é importante entender como as flutuações econômicas têm afetado o comportamento desta desigualdade. Em outras palavras, é necessário saber se ocorreram alterações na desigualdade da renda dos salários e, se isso ocorreu, em que direção e quais os fatores determinantes.

Estudos que analisam a desigualdade de renda, suas causas e efeitos são diversos. Dentre eles, destacam-se estudos buscando relacionar a desigualdade de renda com o crescimento econômico, e, dentre estes, uma possível base teórica, é a chamada hipótese de Kuznets (1955). A pergunta que Kuznets procurava responder com sua hipótese era: tomando-se a distribuição inicial histórica de ativos como dada, as desigualdades pioram ou melhoram ao longo do tempo? Como a renda afeta a desigualdade? A hipótese de Kuznets para a relação entre desigualdade e renda per capita, postula que em economias com baixo nível de desenvolvimento, essencialmente agrícolas, a desigualdade é baixa, pois, quando existe pouco a ser distribuído, a concentração é baixa. Quando começa a ocorrer crescimento econômico e a economia passa para uma fase industrial, as desigualdades aumentam e só irão diminuir quando uma fase avançada do processo de desenvolvimento for atingida.

Neste trabalho, o objetivo não é testar a existência ou não da curva de Kuznets, mas sim partir desta discussão entender o atual estágio de desenvolvimento da economia e, especialmente, dos diferentes setores da indústria do Rio Grande do Sul. Para atingir os objetivos propostos, este trabalho está estruturado como segue. Na próxima seção, são apresentados os resultados das mudanças no mercado industrial de trabalho no período 1996-2005, com especial destaque para ocupação, nível de escolaridade e rendimentos por setor de atividade. Na seção três, são apresentados os procedimentos metodológicos para estimação dos determinantes das variações na desigualdade da renda dos trabalhadores da indústria gaúcha. Na parte quatro, são apresentados e analisados os resultados e, por último, são feitas as considerações finais.

\section{Características e Mudanças de 1996 a 2005 no Emprego Industrial no RS}

Dentre os setores industriais, o de alimentos e bebidas e o de calçados são os que geraram o maior número de empregos no Rio Grande do Sul, tanto em 1996 quanto em 2005 (Tabela 1). Porém, enquanto no setor de alimentos e bebidas o número de trabalhadores assalariados aumentou em 34,15\%, neste período, no setor de calçados, a expansão foi de somente $8,73 \%$. 
Possivelmente, a causa da diferença seja o fato de o primeiro setor ser voltado para o abastecimento do mercado interno, enquanto o setor de calçados ter uma atuação importante no mercado externo, em que enfrenta a competição de outros países como a China. Setores que tiveram grande expansão no emprego de trabalhadores assalariados, neste período, são o de material de transporte $(90,07 \%)$, mecânica $(41,25 \%)$ e química $(36,28 \%)$.

Tabela 1 - Número total de trabalhadores assalariados em doze setores industriais do Rio Grande do Sul em 1996 e 2005 e sua variação percentual neste período.

\begin{tabular}{l|c|c|c}
\hline \multirow{2}{*}{\multicolumn{1}{c|}{ Indústrias }} & \multicolumn{2}{c|}{ N úmero total de trabalhadores } & \multirow{2}{*}{$\begin{array}{c}\text { Variação percentual } \\
\text { de 1996 a 2005 }\end{array}$} \\
\cline { 2 - 3 } & 1996 & 2005 & 34,15 \\
\hline A limentos e bebidas & 83434 & 111923 & 14,18 \\
\hline Borracha, fumo e couro & 40123 & 45814 & 8,73 \\
\hline Calçados & 116602 & 126764 & 19,10 \\
\hline Elétrica e de comunicações & 12620 & 15030 & 30,28 \\
\hline M adeira e mobiliário & 36851 & 48009 & 90,07 \\
\hline M aterial de transporte & 18841 & 35811 & 41,25 \\
\hline M ecânica & 34606 & 48881 & 26,09 \\
\hline M etalúrgica & 44222 & 55758 & 10,43 \\
\hline M ineral não metálica & 13270 & 14654 & 31,81 \\
\hline Papel e gráfica & 21181 & 27918 & 36,28 \\
\hline Q uímica & 34177 & 46575 & 26,03 \\
\hline Têxtil & 21851 & 27538 & 26,56 \\
\hline TO TA L & 477778 & 604695 & \\
\hline
\end{tabular}

Fonte: RAIS - Ministério do Trabalho e Emprego

A Tabela 2 mostra que, de 1996 a 2005, a expansão no número de trabalhadores assalariados nos doze setores analisados da indústria do Rio Grande do Sul foi de aproximadamente de 27\%. Este aumento ocorreu, principalmente, na faixa salarial de um a dois salários mínimos, em que o aumento foi de $152 \%$. 
Tabela 2 - Número de trabalhadores de doze setores industriais do Rio Grande do Sul por nível salarial (em número de salários mínimos) e de escolaridade em 1996 e 2005 e sua variação percentual (\%) neste período.

\begin{tabular}{|c|c|c|c|c|c|c|c|}
\hline \multirow{2}{*}{ Nível salarial } & \multicolumn{2}{|c|}{ A no } & \multirow{2}{*}{$\%$} & \multirow{2}{*}{ Escolaridade } & \multicolumn{2}{|c|}{ Ano } & \multirow{2}{*}{$\%$} \\
\hline & 1996 & 2005 & & & 1996 & 2005 & \\
\hline A té 1,00 & 7353 & 11116 & 51 & A nalfabeto & 6708 & 2045 & -70 \\
\hline 1,01 a 2,00 & 102328 & 258363 & 152 & 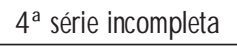 & 50512 & 21983 & -56 \\
\hline 2,01 a 3,00 & 141238 & 149355 & 6 & 4 a série completa & 95188 & 49233 & -48 \\
\hline 3,01 a 4,00 & 69589 & 63496 & -9 & 8a série incompleta & 153346 & 140846 & -8 \\
\hline 4,01 a 5,01 & 43190 & 35934 & -17 & 8a série completa & 70465 & 119841 & 70 \\
\hline 5,01 a 7,00 & 45677 & 37126 & -19 & 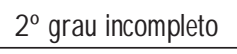 & 36455 & 71842 & 97 \\
\hline 7,01 a 10,00 & 30942 & 21055 & -32 & 20 grau completo & 38204 & 145088 & 280 \\
\hline 10,01 a 15,00 & 17866 & 12156 & -32 & Superior incompleto & 12981 & 30661 & 136 \\
\hline 15,01 a 20,00 & 7232 & 4906 & -32 & Superior completo & 11207 & 23156 & 107 \\
\hline$M$ ais de 20 & 9705 & 6185 & -36 & & & & \\
\hline Ignorada & 2658 & 5003 & 88 & & & & \\
\hline TO TAL & 477778 & 604695 & 27 & TO TA L & 477778 & 604695 & \\
\hline
\end{tabular}

Fonte: RAIS - Ministério do Trabalho e Emprego

Observação: Os doze setores industriais são os mesmos constantes na Tabela 1.

Todos os aumentos no emprego ocorreram nas faixas salariais de até três salários mínimos. Em todas as faixas superiores a três mínimos houve redução do emprego assalariado. Esta redução foi tanto maior, em termos percentuais, quanto mais elevada a faixa salarial. Ocorreu, portanto, de 1996 a 2005, um achatamento salarial na indústria do Rio Grande do Sul.

Por outro lado, examinando-se o nível de escolaridade dos trabaIhadores assalariados da indústria do RS (Tabela 2) verifica-se que houve uma elevação no mesmo. Houve um aumento de 106.884 trabaIhadores assalariados com o nível de escolaridade de $2^{\circ}$ grau completo, ou seja, de $280 \%$.

Em termos percentuais, seguem os aumentos de trabalhadores com escolaridade superior incompleto (136\%), superior completo (107\%) e $2^{\circ}$ grau incompleto (97\%). 
A participação dos trabalhadores com escolaridade de 8a série incompleta ou inferior diminuiu neste período. Houve, portanto, uma elevação do nível médio de escolaridade do trabalhador industrial do RS, enquanto o seu nível médio de salários diminuiu.

A pergunta que fica é: a indústria se modernizou, usando novas tecnologias, em que as máquinas realizam as tarefas antes executadas pela mão de obra com menor escolaridade? Assim, a expansão da indústria se realizaria, principalmente, via maior emprego da mão de obra com maior escolaridade. Porém, se a oferta daquela com maior escolaridade cresce mais do que a demanda, ainda assim, o seu salário médio, em termos de salários mínimos, se reduziria ao longo do tempo.

A Tabela 3 apresenta o número médio de salários mínimos recebidos pelo trabalhador da indústria do RS, por nível de escolaridade, em 1996 e 2005.

Para se chegar a estes valores, o procedimento utilizado é como segue. Os dados da RAIS do Ministério do Trabalho e Emprego informam o número de trabalhadores de cada setor industrial por município, faixa salarial e por nível de escolaridade. Há um total de doze faixas salariais consideradas que, expressas em salários mínimos, são as seguintes: 1) até 0,$50 ; 2$ ) de 0,51 a 1,00; 3) de 1,01 a 1,50;4) de 1,51 a 2,00; 5) de 2,01 a 3,00; 6) de 3,01 a 4,00; 7) de 4,01 a 5,00; 8) de 5,01 a 7,$00 ; 9$ ) de 7,01 a 10,00; 10) de 10,01 a 15,00; 11) de 15,01 a 20,00; 12) mais de 20,00 salários mínimos.

Para a estimativa do total de salários mínimos recebidos pelos trabalhadores com determinado nível de escolaridade considerou-se para cada faixa salarial um número médio de salários mínimos equivalente ao ponto médio desta faixa. Assim, o número de salários mínimos (SM) por trabalhador considerado nas faixas salariais acima referidas é: 1) $0,25 \mathrm{SM}$; 2) 0,75 SM; 3) $1,25 \mathrm{SM}$; 4) $1,75 \mathrm{SM}$; 5) 2,5 $\mathrm{SM}$; 6) 3,5 SM; 7) 4,5 SM; 8) 6,0 SM; 9) $8,5 \mathrm{SM}$; 10) $12,5 \mathrm{SM}$; 11) 17,5 $\mathrm{SM}$; 12) $25 \mathrm{SM}$. Com relação a esta última faixa, como não existe um limite superior escolheu-se arbitrariamente o valor de $25 \mathrm{SM}$. A influência desta faixa sobre o valor total é pequena, pois pouquíssimos trabalhadores recebem mais de 20 SM.

Multiplicando o salário médio de cada faixa pelo número de trabalhadores que se encontram na mesma e somando estes produtos sobre todas as faixas salariais, dentro de determinado nível de escolaridade, chega-se ao total de salários auferidos pelo conjunto dos trabalhadores com essa escolaridade. A divisão desse total pelo número de trabalhadores fornece a estimativa do salário médio auferido pelo trabalhador com este grau de instrução. 
A Tabela 3 mostra que em todos os níveis de escolaridade o salário médio por trabalhador, em termos de salários mínimos, diminuiu de 1996 para 2005.

Tabela 3 - Número médio de salários mínimos recebidos pelo trabalhador assalariado da indústria no Rio Grande do Sul em 1996 e 2005 e variação em termos percentuais.

\begin{tabular}{|c|c|c|c|}
\hline \multirow[t]{2}{*}{ N ível de escolaridade } & \multicolumn{2}{|c|}{$\begin{array}{l}\text { N úmero médio de salários mínimos por } \\
\text { trabalhador }\end{array}$} & \multirow[t]{2}{*}{ V ariação percentual } \\
\hline & Ano de 1996 & Ano de 2005 & \\
\hline A nalfabeto & 3,29 & 2,07 & $-37,1$ \\
\hline 4 a série incompleta & 3,34 & 2,40 & $-28,1$ \\
\hline 4 a série completa & 3,35 & 2,43 & $-27,5$ \\
\hline 8ª série incompleta & 3,61 & 2,41 & $-33,2$ \\
\hline 8ạ série completa & 4,32 & 2,67 & $-38,2$ \\
\hline $2 \stackrel{0}{\text { grau incompleto }}$ & 4,48 & 2,51 & $-44,0$ \\
\hline $2 \stackrel{0}{\text { grau }}$ completo & 6,84 & 3,62 & $-47,1$ \\
\hline Superior incompleto & 9,74 & 5,65 & $-42,0$ \\
\hline Superior completo & 15,38 & 11,35 & $-26,2$ \\
\hline Total & 4,40 & 3,27 & $-25,7$ \\
\hline
\end{tabular}

Fonte: RAIS - Ministério do Trabalho e Emprego

Observa-se que a maior redução no número médio de salários mínimos por trabalhador, de 1996 a 2005, ocorreu no nível de escolaridade de $2^{\circ}$ grau completo. Foi esse 0 nível de escolaridade cuja participação no total dos trabalhadores assalariados teve o maior aumento, tanto em termos relativos como absolutos, de 1996 para 2005 (vide Tabela 2).

Nos outros níveis de escolaridade em que houve grande expansão no emprego, como no $2^{\circ}$ grau incompleto e no superior incompleto, também houve grande redução no salário médio. Esta redução salarial foi muito menor no superior completo, apesar do grande aumento percentual no número de trabalhadores neste nível.

Isto parece indicar que a oferta de mão-de-obra com um nível de escolaridade inferior ao superior completo cresceu muito mais do que a demanda. A oferta de mão-de-obra com a escolaridade de 
superior completo também teria crescido mais do que a demanda, mas a um ritmo menos intenso.

Verificou-se que o salário médio na indústria do Rio Grande do Sul teve uma redução de $25,7 \%$ de 1996 a 2005 (Tabela 3). Ao mesmo tempo, pela Tabela 2, constata-se que a escolaridade do trabalhador assalariado desta indústria aumentou neste período. A pergunta que segue é: a distribuição destes salários entre os trabalhadores se tornou mais equitativa nesse período, convergindo os salários para um nível mais baixo para o grande conjunto desses trabalhadores?

Da mesma forma, a distribuição dos níveis de escolaridade dos trabalhadores industriais se tornou mais igual nesse período, com a grande maioria deles obtendo um grau de instrução mais elevado?

Estas perguntas são respondidas através do cálculo de índices de Gini da distribuição dos salários e dos níveis de escolaridade.

Segue a metodologia utilizada no cálculo dos índices de Gini.

\section{M etodologia}

\subsection{Cálculo do índice de $\mathrm{G}$ ini da distribuição dos salários dos} trabalhadores da indústria

Calcula-se, inicialmente, o índice de Gini da distribuição dos salários dos trabalhadores da indústria do Rio Grande do Sul, em relação ao total do Estado, para cada um dos doze setores industriais.

Com base no número absoluto de trabalhadores em cada faixa salarial e no total dos trabalhadores do setor industrial no RS sobre as doze faixas, é calculada a proporção $\pi_{\mathrm{h}}$ de trabalhadores da h-ésima faixa.

Estima-se o valor total dos salários dos trabalhadores de cada faixa salarial pressupondo que o salário médio em cada faixa salarial corresponda ao ponto central da faixa, conforme visto no item anterior.

Multiplicando o salário médio de cada faixa salarial pelo número de trabalhadores situados na mesma obtém-se o valor total dos salários nessa faixa. Com base nestes totais salariais por faixa e no total geral do setor no Estado, calcula-se a proporção dos salários $X_{h}$ na h-ésima faixa em relação a este total do RS para cada setor.

A seguir calcula-se o somatório $\phi_{h}$ das proporções salariais até cada faixa $h$.

$$
\phi_{h}=\sum_{j=1}^{h} X_{j}
$$


Segundo Hoffmann (1998, cap.16), sendo $\phi_{h-1}$ o somatório das proporções salariais até a faixa anterior a $h$, calcula-se 0 índice de Gini da desigualdade entre as faixas salariais $G_{e}$ como sendo igual a:

$$
G_{e}=1-\sum_{h=1}^{12}\left(\phi_{h-1}+\phi_{h}\right) \pi_{h}
$$

O índice de Gini G para o conjunto dos trabalhadores de cada setor industrial no Estado é dado por $G=G_{h}+G_{e}$ onde $G_{h}$ é o índice de Gini da distribuição dentro da h-ésima faixa salarial e $G_{e}$ é o índice da desigualdade entre as faixas. Ao se considerar $G_{\text {e }}$ como uma proxi de $G$ está se considerando que haja perfeita igualdade na distribuição salarial dentro de cada faixa, ou seja, $G_{h}=0$.

Da mesma forma, calcula-se o índice de Gini da distribuição dos salários para cada setor dentro de cada município. Assim, obtémse um conjunto de dados em que as observações são os municípios em que o setor industrial considerado tenha trabalhadores assalariados. Isto possibilita análises através de regressões estatísticas para explicar a variação do índice de Gini que tenha ocorrido de 1996 para 2005.

Para essas regressões estatísticas, são considerados os valores de $G_{e}$ da distribuição dos salários, ao nível dos municípios, para os anos de 1996 ( $\mathrm{G}_{\mathrm{e}}$ 1996) e 2005 (G 2005). A variável explicada na regressão consiste no $\Delta \mathrm{G}_{\mathrm{e}}$ salário $=\mathrm{G}_{\mathrm{e}}$ salário2005 $-\mathrm{G}_{\mathrm{e}}$ salário1996.

\subsection{Cálculo do índice de $G$ ini da distribuição dos anos de escola dos trabalhadores da indústria}

Os dados da RAIS informam o número de trabalhadores incluídos em cada um dos nove níveis de escolaridade. Calcula-se o índice de Gini da distribuição dos anos de escolaridade por setor industrial. Para este cálculo, considera-se uma escolaridade média, ou seja, um número médio de anos de escola para o trabalhador em cada nível de escolaridade. Assim pode-se estimar o número de anos de escola dos trabalhadores de cada setor industrial por nível de escolaridade. 0 valor por nível de escolaridade corresponde ao número de trabalhadores incluídos no mesmo multiplicado pela escolaridade média neste nível. Após, estima-se o total de anos de escola de todos os trabalhadores do setor pela soma dos totais em cada nível escolar. Desta forma é possível avaliar como se distribuem os anos de escola dos trabalhadores de um setor industrial, entre os diversos níveis, através de um índice de Gini.

Os valores médios de anos de escola considerados neste estudo (entre parênteses) para os vários níveis de escolaridade são: analfabeto(0); 
$4^{\text {a }}$ série incompleta (2); $4^{\text {a }}$ série completa (4); $8^{\text {a }}$ série incompleta (6); $8^{\text {a }}$ série completa $(8) ; 2^{\circ}$ grau incompleto $(9,5) ; 2^{\circ}$ grau completo (11); superior incompleto (13); superior completo (15).

O índice de Gini da distribuição dos anos de escola entre os trabalhadores é calculado da mesma forma que no caso da distribuição dos salários, detalhada anteriormente. Obtêm-se os valores de $\mathrm{Ge}$ da distribuição dos anos de escola, em relação a cada setor, para os anos de 1996 (Ge1996) e 2005 (Ge2005).

\subsection{Regressões estatísticas}

Com a finalidade de encontrar alguma explicação para a variação do índice de Gini da distribuição dos salários, de 1996 a 2005, realiza-se uma regressão estatística para cada setor industrial.

As regressões estatísticas têm por variável explicada a mudança ocorrida na distribuição dos salários, no período analisado, ou seja, o índice de Gini de 2005 menos o índice de Gini de 1996. As variáveis explicativas são as mudanças na participação dos trabaIhadores do setor e do município nos níveis de escolaridade expressas em diferenças de percentuais. Assim, por exemplo, considera-se o percentual dos trabalhadores, dentre os do setor e do município, que, em 2005, tinham a $8^{a}$ série incompleta, subtraindo-se deste percentual aquele referente aos trabalhadores, com as mesmas características, só que relativo ao ano de 1996. O mesmo procedimento foi aplicado a todos os níveis de escolaridade. Nas regressões, somente foram incluídas as diferenças referentes aos níveis da 8a série incompleta até o superior. A inclusão de todos os níveis resultaria em multicolinearidade perfeita entre estas variáveis.

Outra variável explicativa é a variação percentual no salário médio ou per capita do trabalhador do setor e município de 1996 a 2005. É incluída, também, como variável explicativa, a dimensão do setor no município, expressa em número de trabalhadores em 2005. Considera-se, ainda, a expansão do setor no município em termos de variação percentual do número de trabalhadores assalariados, existentes no mesmo, de 1996 a 2005.

\section{Resultados}

\subsection{M udanças nos índices de $G$ ini da distribuição de salários e da} escolaridade nos setores industriais

Foram estimados os índices de Gini da distribuição dos salários e dos níveis de escolaridade em relação a cada um dos doze setores industriais (Tabela 4). 
A maior parte dos doze setores industriais analisados apresentou redução no índice de Gini referente aos salários no período de 1996 a 2005. Examinando-se as tabelas 8 a 13, no anexo, verifica-se que em todos os setores houve aumento na participação percentual dos trabalhadores na faixa salarial de um a dois salários mínimos e redução na participação em faixas de salários mais elevados. Isto significa que a maior igualdade na distribuição dos salários ocorreu devido a um achatamento salarial.

Os dois únicos setores que tiveram um aumento, porém pequeno, no índice de Gini, no período, foram o de Material de transporte e o de Mecânica. Através das tabelas do anexo, observa-se que nesses dois setores os aumentos na participação percentual na faixa de um a dois salários mínimos foram menores, ocorrendo também acréscimos na participação em outras faixas salariais. Estes dois setores apresentam as menores concentrações, em termos percentuais, de trabalhadores na faixa de um a dois salários mínimos, em 2005, (Tabela 6 do anexo).

Tabela 4 - Índices de Gini da distribuição dos salários e dos níveis de escolaridade dos trabalhadores na indústria do Rio Grande do Sul em 1996 e 2005.

\begin{tabular}{l|c|c|c|c|c|c}
\hline \multirow{2}{*}{ Indústria } & \multicolumn{3}{|c|}{$\begin{array}{c}\text { Indice de G ini } \\
\text { referente a0s salários }\end{array}$} & \multicolumn{3}{c}{$\begin{array}{c}\text { Índice de G ini } \\
\text { referente à escolaridade }\end{array}$} \\
\cline { 2 - 7 } & 1996 & 2005 & Diferença & 1996 & 2005 & Diferença \\
\hline A limentos e bebidas & 0,36 & 0,33 & $-0,04$ & 0,30 & 0,22 & $-0,08$ \\
\hline Borracha, fumo e couro. & 0,41 & 0,39 & $-0,02$ & 0,28 & 0,22 & $-0,06$ \\
\hline Calçados & 0,33 & 0,31 & $-0,03$ & 0,24 & 0,20 & $-0,04$ \\
\hline Elétrica e de comunicações & 0,40 & 0,40 & 0,00 & 0,24 & 0,13 & $-0,11$ \\
\hline M adeira e mobiliário & 0,35 & 0,28 & $-0,06$ & 0,23 & 0,20 & $-0,03$ \\
\hline M aterial de transporte & 0,34 & 0,36 & 0,01 & 0,23 & 0,16 & $-0,07$ \\
\hline Mecânica & 0,39 & 0,40 & 0,01 & 0,25 & 0,17 & $-0,08$ \\
\hline M etalúrgica & 0,37 & 0,35 & $-0,01$ & 0,27 & 0,18 & $-0,08$ \\
\hline M ineral não metálica & 0,40 & 0,33 & $-0,06$ & 0,29 & 0,23 & $-0,06$ \\
\hline Papel e gráfica & 0,44 & 0,42 & $-0,02$ & 0,24 & 0,16 & $-0,08$ \\
\hline Q uímica & 0,48 & 0,48 & 0,00 & 0,25 & 0,18 & $-0,07$ \\
\hline Têxtil & 0,36 & 0,29 & $-0,07$ & 0,21 & 0,17 & $-0,05$ \\
\hline
\end{tabular}

Fonte: RAIS - Ministério do Trabalho e Emprego 
Os setores com a maior redução neste índice são Madeira e Mobiliário, Mineral não metálica e Têxtil. Estes setores tiveram aumentos acentuados na participação percentual dos trabalhadores na faixa de um a dois salários mínimos e grande redução na participação nas faixas acima, especialmente nas de três a dez salários mínimos (Tabelas 10, 12 e 13 do anexo). Estes resultados mostram, portanto, que houve um achatamento salarial bem acentuado nesses três setores.

Estes três setores são, após o setor de calçados ( $5^{\circ}$ colocado em redução no índice de Gini), aqueles que apresentam a maior concentração de trabalhadores na faixa salarial de um a dois salários mínimos (Tabela 6 do anexo).

Os quatro setores que, ou tiveram aumento no índice de Gini da distribuição de salários como Material de transporte e Mecânica, ou não tiveram variação neste índice como Elétrica e de Comunicações e o de Química, são os que apresentam a maior participação percentual dos trabalhadores na faixa salarial de mais de dez salários mínimos (Tabela 6 do anexo). Seriam, portanto setores que exigiriam mão-de-obra mais especializada. A Tabela 7 do anexo mostra que esses quatro setores são os que apresentaram, em 2005, as maiores participações percentuais de trabalhadores no nível de escolaridade superior completo.

Quanto ao índice de Gini referente aos níveis de escolaridade dos trabalhadores da indústria do RS, a Tabela 4 mostra que houve uma redução em todos os setores industriais. As Tabelas 6 a 13 do anexo mostram que houve redução na participação percentual dos trabalhadores nos níveis de escolaridade que vai do analfabeto até a 8a série incompleta, em todos os setores. Houve elevação na participação dos trabalhadores nos níveis de escolaridade mais elevados. A elevação na participação no $2^{\circ}$ grau completo foi a maior em todos os setores industriais. Isto mostra que há uma maior igualdade entre os níveis de escolaridade dos trabalhadores e que esta igualdade ocorre a um nível mais elevado de escolaridade.

Infelizmente, os dados não permitem concluir se essa igualdade, a um nível de escolaridade mais elevado, ocorre porque os analfabetos e os com menor grau de instrução frequentaram alguma escola e se escolarizaram ou se foram substituídos por outros trabalhadores com maior nível de escolaridade.

Nos três setores em que a redução do índice de Gini referente aos níveis de escolaridade foi menor são: Calçados, Madeira e Mobiliário e Têxtil. Estes setores apresentaram, em 2005, as menores participações dos trabalhadores no nível de escolaridade superior completo 
e também superior incompleto juntamente com o setor Mineral não metálica (Tabela 7 do anexo).

Na maioria dos setores em que a redução do índice de Gini da distribuição dos níveis de escolaridade foi maior (Elétrica e de Comunicações, Material de transporte, Mecânica, Metalúrgica, Papel e Gráfica e Química) as participações percentuais dos trabalhadores nos níveis de escolaridade de $2^{\circ}$ grau completo e superiores são mais elevadas em 2005 (Tabela 7 do anexo). Faz exceção a esta relação o setor de Alimentos e Bebidas que, apesar de ter tido uma grande redução no índice de Gini, não apresenta uma participação tão elevada de trabalhadores nos níveis mais altos de escolaridade se comparado aos outros setores.

Esta relação entre redução do índice de Gini da distribuição dos níveis de escolaridade e participação maior nos níveis mais elevados de escolaridade parece confirmar que a convergência da igualdade na escolaridade vai na direção de um maior grau de instrução dos trabalhadores da indústria do RS.

\subsection{Resultados das regressões}

Através de regressões estatísticas procura-se encontrar algumas variáveis associadas às mudanças no índice de Gini da distribuição dos salários em cada um dos setores industriais.

Os resultados destas regressões estão apresentados na Tabela 5. Nestas regressões estatísticas são excluídos os municípios com menos de cinco trabalhadores assalariados no setor respectivo. Não estão incluídos, nesta Tabela, os resultados da regressão referente à indústria elétrica e de comunicações, porque, devido ao pequeno número de observações, ela não foi estatisticamente significante.

Em nove dos doze setores, observa-se que o aumento percentual do salário per capita eleva o índice de Gini da distribuição dos salários, ou seja, torna-a mais desigual. Neste caso, estaria a grande parte da indústria do RS na parte crescente da curva de Kuznets.

Em três setores (alimentos e bebidas, calçados e mecânica), quanto maior a indústria no município, mais desigual é a distribuição dos salários. Isto poderia se explicar pelo aumento do número de cargos de chefia e de outros que exijam mais qualificação, gerando desigualdades nos salários, quando a fábrica se torna maior.

$\mathrm{Na}$ indústria química, o impacto do tamanho da indústria no município sobre a desigualdade na distribuição dos salários é o inverso dos três casos acima. Examinando-se os dados, observa-se que nos municípios onde há muitos trabalhadores assalariados neste setor, a mudança no índice de Gini foi, em geral, pequena ou nula. Isto 
explica porque o índice de Gini nesta indústria, ao nível do Estado, não variou (Tabela 4). Este índice variou mais nos municípios em que o número de assalariados é menor. A explicação pode ser que nas fábricas maiores a estrutura de chefias e de cargos mais qualificados, portanto a distribuição dos salários permaneceu a mesma de 1996 para 2005. Nas fábricas menores, com a sua expansão, houve necessidade da criação de chefias e de novos cargos e da redistribuição dos salários. Assim, quando se observa os dados sobre os municípios, conclui-se que, quanto maior o número de trabalhadores desta indústria no mesmo, menor foi a variação no índice de Gini. Isto resulta neste efeito inverso do tamanho da indústria sobre a variação deste índice.

Em quatro setores industriais (madeira e mobiliário, mecânica, papel e gráfica e química) quanto maior a expansão da indústria no município, em termos de variação percentual no número de trabaIhadores assalariados de 1996 para 2005, tanto mais desigual se tornou o índice de Gini. Isto seria a situação já comentada anteriormente, em que a fábrica que se expande necessita de maior número de cargos de chefia e de outros com maior qualificação, gerando uma distribuição mais desigual de salários.

No setor de alimentos e bebidas, ocorreu o contrário, ou seja, com o aumento do número de trabalhadores, houve redução do índice de Gini referente à distribuição dos salários. Convém comparar esse setor com o de madeira e mobiliário. Coincidentemente, ambos apresentam 225 municípios com cinco ou mais trabalhadores assalariados no respectivo setor (Tabela 5). Nas Tabelas 6 e 7 do anexo, observa-se que, em 2005, a distribuição percentual dos trabalhadores por faixas salariais e por níveis de escolaridade em cada um desses dois setores é muito semelhante. Mas, examinando as Tabelas 8 e 10 do anexo, verifica-se que o aumento na faixa salarial de um a dois salários mínimos e a queda nas faixas superiores foi de 32 pontos percentuais no setor de alimentos e bebidas e de apenas 18 pontos percentuais no setor de madeira e mobiliário.

Constata-se, portanto, que a expansão do setor de alimentos e bebidas, de 1996 para 2005, ocasionou uma redução de salários para um maior número de trabalhadores, em termos absolutos e percentuais, do que a do setor de madeira e mobiliário. Devido a um maior número de trabalhadores sendo deslocado para um nível salarial mais baixo, no setor de alimentos e bebidas, ocorreu a relação inversa entre expansão do setor e índice de Gini.

Examinando-se os impactos das mudanças ocorridas nos níveis de escolaridade dos trabalhadores sobre a distribuição nos seus 
níveis salariais verifica-se que os mesmos variam muito conforme 0 setor industrial.

Esperar-se-ia que níveis de escolaridade mais elevados estivessem associados a maiores níveis salariais. Assim, aumentos nas participações percentuais dos trabalhadores nos níveis mais elevados de escolaridade aumentariam o índice de Gini, pois estes trabalhadores receberiam salários mais altos que os da grande maioria. 0 oposto aconteceria com os aumentos nas participações dos trabalhadores nos níveis mais baixos de escolaridade. Em alguns setores industriais, foi exatamente isso que aconteceu.

No setor de alimentos e bebidas, o aumento na participação dos trabalhadores no nível de escolaridade de superior incompleto aumenta o índice de Gini. Significaria que os trabalhadores com esta escolaridade ganhariam salários distintos dos demais. Em 2005, o salário médio do trabalhador com escolaridade de superior incompleto era de 5,65 salários mínimos (Tabela 3) e o salário médio do trabaIhador deste setor era de 2,73 salários mínimos (Tabela 6 do anexo)

No setor de borracha, fumo e couro, uma maior participação dos trabalhadores com $8^{a}$ série incompleta reduz o índice de Gini. 0 salário médio nesse setor, em 2005, foi de 3,26 salários mínimos (Tabela 6 do anexo) e o do trabalhador com 8 a série incompleta variou de 3,61 para 2,41 salários mínimos de 1996 a 2005 (Tabela 3).

No setor de calçados, uma maior participação dos trabalhadores nos níveis de $8^{a}$ série incompleta e de $2^{\circ}$ grau completo reduz o índice de Gini e nos níveis de superior incompleto e completo aumenta o índice de Gini. Assim, o salário da maioria dos trabalhadores deste setor estaria mais próximo daquele recebido pelos que apresentam os dois primeiros níveis de instrução (vide Tabela 3 do texto e Tabela 6 no anexo).

Tabela 5 - Efeitos das mudanças nas participações (em percentuais) dos trabalhadores nos níveis de escolaridade, no salário per capita e no número de trabalhadores e da dimensão da indústria no município sobre a variação no índice de Gini da distribuição de salários.

\begin{tabular}{|c|c|c|c|c|c|c|c|c|c|c|c|c|}
\hline \multirow{2}{*}{ Variáveis } & \multirow{2}{*}{$\begin{array}{c}\text { Coef } \\
\text { Sig Est }\end{array}$} & \multicolumn{11}{|c|}{ Indústria } \\
\hline & & A lim. Beb & $\begin{array}{c}\text { Bor. fumo } \\
\text { couro }\end{array}$ & Calçados & Mad Mob & $\begin{array}{c}\text { Mat } \\
\text { transp }\end{array}$ & Mecan & M etal & $\begin{array}{c}\text { M in não } \\
\text { met }\end{array}$ & $\begin{array}{l}\text { Papel } \\
\text { gráf. }\end{array}$ & Q uímica & Têxtil \\
\hline \multirow{2}{*}{ Constante } & Coef & 0,006 & $-0,004$ & $-0,003$ & $-0,03$ & 0,00 & 0,00 & $-0,04$ & $-0,02$ & $-0,01$ & 0,00 & $-0,03$ \\
\hline & S. E*. & 0,63 & 0,76 & 0,81 & 0,03 & 0,94 & 0,97 & 0,00 & 0,14 & 0,37 & 0,86 & 0,06 \\
\hline \multirow{2}{*}{ 8a série incomp. } & Coef & $-0,03$ & $-0,01$ & $-0,09$ & $-0,004$ & 0,18 & $-0,05$ & $-0,05$ & 0,02 & 0,02 & $-0,17$ & 0,002 \\
\hline & S. E. & 0,47 & 0,74 & 0,04 & 0,91 & 0,02 & 0,24 & 0,18 & 0,57 & 0,71 & 0,005 & 0,97 \\
\hline \multirow{2}{*}{ 8ミa série Compl. } & Coef & 0,04 & $-0,11$ & $-0,05$ & $-0,02$ & 0,30 & 0,02 & 0,10 & 0,05 & 0,09 & 0,04 & 0,03 \\
\hline & S. E. & 0,29 & 0,04 & 0,30 & 0,56 & 0,00 & 0,62 & 0,02 & 0,29 & 0,07 & 0,46 & 0,58 \\
\hline
\end{tabular}




\begin{tabular}{|c|c|c|c|c|c|c|c|c|c|c|c|c|}
\hline \multirow{2}{*}{ 20 grau incomp. } & Coef & 0,00 & 0,02 & $-0,01$ & $-0,02$ & 0,07 & 0,21 & 0,04 & 0,07 & 0,05 & $-0,10$ & $-0,04$ \\
\hline & S. E. & 0,94 & 0,79 & 0,88 & 0,76 & 0,51 & 0,00 & 0,54 & 0,38 & 0,39 & 0,07 & 0,68 \\
\hline \multirow{2}{*}{ 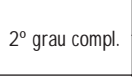 } & Coef & $-0,02$ & $-0,05$ & $-0,20$ & 0,05 & 0,08 & $-0,09$ & 0,05 & 0,08 & 0,01 & $-0,12$ & 0,06 \\
\hline & S. E. & 0,61 & 0,51 & 0,02 & 0,39 & 0,45 & 0,04 & 0,26 & 0,21 & 0,90 & 0,14 & 0,29 \\
\hline \multirow{2}{*}{ Superior incomp. } & Coef & 0,24 & 0,09 & 0,79 & $-0,02$ & 0,72 & $-0,33$ & 0,56 & 0,60 & 0,12 & 0,15 & 0,26 \\
\hline & S. E. & 0,08 & 0,74 & 0,01 & 0,88 & 0,14 & 0,07 & 0,00 & 0,03 & 0,28 & 0,42 & 0,09 \\
\hline \multirow{2}{*}{$\begin{array}{l}\text { Superior } \\
\text { completo }\end{array}$} & Coef & $-0,15$ & 0,21 & 1,49 & 0,04 & 0,08 & 0,21 & 0,11 & 0,15 & 0,07 & 0,47 & 0,33 \\
\hline & S. E. & 0,34 & 0,33 & 0,01 & 0,77 & 0,79 & 0,15 & 0,27 & 0,72 & 0,69 & 0,01 & 0,16 \\
\hline \multirow{2}{*}{$\begin{array}{c}\text { Var. Per. salário } \\
\text { per capita }\end{array}$} & Coef & 0,002 & 0,001 & 0,002 & 0,001 & 0,001 & $4,8 \mathrm{E}-04$ & 0,001 & $8,9 \mathrm{E}-04$ & 0,00 & $-4,8 \mathrm{E}-06$ & 0,001 \\
\hline & S. E. & 0,00 & 0,03 & 0,00 & 0,00 & 0,096 & 0,03 & 0,00 & 0,04 & 0,35 & 0,96 & 0,00 \\
\hline \multirow{2}{*}{ Total trab. 2005} & Coef & $1,27 \mathrm{E}-05$ & $4,24 \mathrm{E}-06$ & $7,3 \mathrm{E}-06$ & $3, \mathbb{E}-06$ & $2,6 \mathrm{E}-06$ & $1,0 \mathrm{E}-05$ & $4, \mathbb{E}-06$ & $9,2 \mathrm{E}-06$ & $5,4 \mathrm{E}-06$ & $-1,2 \mathrm{E}-05$ & $6, \mathbb{E}-06$ \\
\hline & S. E. & 0,00 & 0,43 & 0,01 & 0,56 & 0,11 & 0,00 & 0,34 & 0,83 & 0,29 & 0,00 & 0,34 \\
\hline \multirow{2}{*}{$\begin{array}{l}\text { Var. Per. } \\
N \text { úmero } \\
\text { trabalhad. }\end{array}$} & Coef & $-2,4 \mathrm{E}-05$ & 5,0 E-0 5 & $-5,5 \mathrm{E}-06$ & $7,0 \mathrm{E}-05$ & $6,5 \mathrm{E}-05$ & $3,5 \mathrm{E}-05$ & $3,3 \mathrm{E}-05$ & $7, \mathbb{E}-05$ & $1 E-04$ & $5,0 \mathrm{E}-05$ & $3,2 E-05$ \\
\hline & S. E. & 0,00 & 0,11 & 0,61 & 0,01 & 0,49 & 0,00 & 0,28 & 0,10 & 0,01 & 0,00 & 0,23 \\
\hline $\mathrm{R}^{2}$ ajustado & & 0,24 & 0,26 & 0,45 & 0,14 & 0,29 & 0,53 & 0,33 & 0,12 & 0,04 & 0,31 & 0,26 \\
\hline № observ. & & 225 & 106 & 110 & 225 & 43 & 72 & 136 & 142 & 108 & 74 & 127 \\
\hline
\end{tabular}

Fonte: RAIS - Ministério do Trabalho e Emprego

* S.E. = significância estatística.

No setor de material de transporte, em que o salário médio em 2005 foi de 5,58 salários mínimos (Tabela 6 do anexo), uma maior participação dos trabalhadores com níveis de escolaridade de $8^{a}$ série incompleta e completa (cujo salário médio é de aproximadamente 2,50 mínimos, conforme Tabela 3 do texto) aumenta a desigualdade dos rendimentos salariais.

No setor de mecânica, o salário médio em 2005 foi de 4,82 salários mínimos (Tabela 6 do anexo). Este valor está entre o que recebia o trabalhador com o superior incompleto e aquele com $02^{\circ}$ grau completo (respectivamente 5,65 e 3,62 salários mínimos, conforme Tabela 3 do texto). Assim, observa-se, na Tabela 5, que uma maior participação dos trabalhadores deste setor com o superior incompleto e dos com $2^{\circ}$ grau completo reduz o índice de Gini. Mas uma maior participação nos níveis de escolaridade de $2^{\circ}$ grau incompleto, cujos rendimentos estão mais afastados desta média do setor contribui para o aumento do índice de Gini.

$\mathrm{Na}$ indústria metalúrgica, o salário médio em 2005 foi de 3,88 salários mínimos. Assim, uma maior participação dos trabalhadores com $8^{a}$ série completa (com 2,67 salários mínimos) ou com curso superior incompleto (5,65 salários mínimos) contribui para o aumento do índice de Gini ou da desigualdade salarial. 
$\mathrm{Na}$ indústria mineral não metálica, (salário médio de 2,60 mínimos) uma maior participação dos trabalhadores com o nível de escolaridade de superior incompleto aumenta a desigualdade na distribuição dos salários. $\mathrm{Na}$ indústria de papel e gráfica, com salário médio de 3,44 salários mínimos, é o nível de escolaridade de $8^{a}$ série completa (média de 2,67 salários mínimos) que conduz a uma maior desigualdade na distribuição dos salários.

$\mathrm{Na}$ indústria química (salário médio de 4,57 salários mínimos) uma maior participação de trabalhadores com a 8a série incompleta e daqueles com 20 grau incompleto (respectivamente, com 2,41 e 2,51 salários mínimos) contribui para a redução do índice de Gini e os com o superior completo (salário médio de 11,35 mínimos) para o seu aumento.

No setor da indústria têxtil, (salário médio de 2,19 salários mínimos) a maior participação dos trabalhadores com superior incompleto (média de 5,65 salários mínimos) contribui para o aumento do índice de Gini.

Verifica-se que o impacto da maior participação de trabalhadores com curso superior completo e também com superior incompleto (exceção da indústria mecânica) nos setores nos quais foram estatisticamente significantes é no sentido do aumento do índice de Gini ou da desigualdade de salários. Porém, o sentido do impacto de uma maior participação dos trabalhadores com nível de escolaridade de $2^{\circ}$ grau completo ou menor varia conforme o setor industrial considerado.

A tendência dos salários nos vários setores industriais, conforme mostram as Tabelas 8 a 13 do anexo, é no sentido de uma redução, tendendo a grande maioria para a faixa de um a dois salários mínimos. Por isso se explica que os níveis de escolaridade mais elevados, com salários mais altos, aumentem o índice de Gini, uma vez que esses salários diferem da tendência geral.

\section{Considerações Finais}

Este estudo permite concluir que, entre 1996 e 2005 ocorreu redução na desigualdade dos rendimentos do trabalho no Rio Grande do Sul. Esta redução na desigualdade ocorreu ao longo de um período marcado por alterações e por oscilações importantes na indústria e com aumento do número de trabalhadores inferior ao crescimento acumulado da produção. Ou seja, ocorreu aumento 
na produtividade do trabalho. Ao mesmo tempo, ocorreu uma elevação do nível de escolaridade dos trabalhadores ocupados no setor industrial. O que mais chama atenção, porém, é que a redução na desigualdade é consequência de um achatamento salarial e do aumento do número de trabalhadores ocupados em empregos de menor remuneração. Em outras palavras, os trabalhadores da indústria gaúcha estão mais qualificados, produzem mais e ganham menos.

A penas quatro dentre os doze setores da indústria não apresentaram redução na desigualdade da distribuição dos salários. Estes são os setores da Indústria elétrica e de comunicações, Material de transporte, Mecânica e o setor da Química. Estes setores em que não se observou redução do índice de Gini da distribuição dos salários são os que apresentam maior participação percentual de trabalhadores na faixa salarial acima de dez salários mínimos. Seriam, portanto, os setores que exigiriam mão-de-obra mais especializada.

Dentre os oito setores em que ocorreu redução no indice de Gini, destacam-se os de Madeira e Mobiliário, Mineral não metálica e Têxtil. Estes três setores apresentam aumentos acentuados na participação relativa dos trabalhadores na faixa salarial de um a dois salários mínimos e grande redução da participação nas faixas mais elevadas, especialmente de três a dez salários mínimos. Este fato indica que houve um achatamento salarial acentuado nestes três setores.

No que tange à desigualdade educacional, todos os setores revelaram redução do índice de Gini. Esta redução ocorreu pela elevação do nível médio de escolaridade do trabalhador em todos os setores industriais analisados. Houve redução na participação relativa de trabalhadores com nível de escolaridade que vai de analfabeto até $8^{a}$ série incompleta e elevação, principalmente, no percentual de trabalhadores com o $2^{\circ}$ grau completo.

Os resultados das regressões estatísticas realizadas mostram que na grande maioria dos setores o aumento do salário per capita eleva o índice de Gini da distribuição dos salários, tornando-a mais desigual. Assim, grande parte da indústria do RS estaria na parte crescente da curva de Kuznets.

Quanto ao efeito da expansão da indústria em uma região, os resultados parecem mostrar que a mesma aumenta o índice de Gini da distribuição de salários. Isto se explicaria pelo fato de que a ampliação 
da indústria na região exigiria um aumento do número de cargos de chefia e de outros que requeiram mais qualificação, gerando, assim, desigualdades nos salários.

Os impactos de mudanças na escolaridade dos trabalhadores sobre a distribuição dos seus salários variam muito conforme o setor industrial. Principalmente, a maior participação de trabalhadores com curso superior completo, e também com o incompleto, geralmente aumenta 0 índice de Gini da distribuição de salários, porque os trabaIhadores com esta qualificação recebem salários acima da média.

Como a tendência dos salários nos vários setores tem sido na direção de uma redução, especialmente para a faixa de um a dois salários mínimos, os trabalhadores com níveis de escolaridade muito elevados, que são remunerados com salários acima deste nível, aumentam o índice de Gini.

\section{Referências}

BAGOLIN, I. P.; GABE, J .; RIBEIRO, E. P. Crescimento e Desigualdade no Rio Grande do Sul: Uma Revisao da Curva de Kuznets para os Municípios Gaúchos (1970-1991). In: $2^{\circ}$ Encontro de Economia Gaúcha, 2004, 2004, Porto Alegre. Anais do $2^{\circ}$ EEG. Porto Alegre. FEE, 2004. v. v.1

BERNI, D. de A. et. al. A Desigualdade Económica do Rio Grande do Sul. Primeiras Investigações sobre a Curva de Kuznets. 1ํ Encontro de Economia Gaúcha (EEG). Porto Alegre. Anais... Cd Room, 2002.

FEE - Fundação de Economia e Estatística do Estado do Rio Grande do Sul. FEE, 2007 (indicadoresFEE www.fee.che.gov.br)

FIELDS, G. S. Poverty, inequality and development. N ew York. Cambridge Press. 1980.

FIELDS, Gary S. Distribuition and Development: a new look at the developing w orld. MIT Press. Cambridge, Massachusetts London, England, 2001.

HOFF MANN, R. Estatística para Economistas. Biblioteca Pioneira de Ciências Sociais. São Paulo. SP. 1998.

IPE, Instituto de Pesquisa Econômica A plicada. www.ipea.gov.br. 2007

KUZNETS, Simon. Economic Growth and Income Inequality. The American Economic Review, v. XLV, n. 01, 1955.

OLIVEIRA, J úlio César de. Desenvolvimento Humano, Desigualdade de Renda e Pobreza nos Conselhos Regionais e Municípios do Rio Grande do Sul entre 1970 e 1991. Porto Alegre: PPGE/UFRGS. Tese de Doutorado, Economia, não publicada, 2001.

RAY, Debraj. Development Economics. Princeton University Press. Princeton, New J ersey, United States of America, 1998.

RAIS - Registro Anual de Infomação Social. Ministério do Trabalho.

Recebido em 03/07/2008.

Aceito em 21/07/2008. 


\section{A nexo}

Tabela 6 - Percentuais de trabalhadores por faixa salarial, em cada setor industrial, e salário médio (em salários mínimos), em 2005.

\begin{tabular}{|c|c|c|c|c|c|c|c|}
\hline \multirow[b]{2}{*}{ Indústrias } & \multicolumn{6}{|c|}{ Faixa salarial (em salários mínimos) } & \multirow{2}{*}{$\begin{array}{l}\text { Salário } \\
\text { Médio }\end{array}$} \\
\hline & A té 1,00 & $\begin{array}{l}1,01 \mathrm{a} \\
2,00\end{array}$ & $\begin{array}{l}2,01 \mathrm{a} \\
3,00\end{array}$ & $\begin{array}{c}3,01 \mathrm{a} \\
5,00\end{array}$ & $\begin{array}{l}5,01 \mathrm{a} \\
10,00 \\
\end{array}$ & $\begin{array}{c}\text { Mais de } \\
10,00\end{array}$ & \\
\hline A limentos e bebidas & 2,4 & 46,4 & 30,1 & 13,6 & 5,6 & 1,9 & 2,73 \\
\hline Borracha, fumo e couro. & 1,3 & 43,1 & 25,0 & 16,7 & 10,7 & 3,4 & 3,26 \\
\hline Calçados & 1,5 & 69,5 & 17,6 & 6,3 & 3,8 & 1,4 & 2,24 \\
\hline Elétrica e de comunicaçōes & 1,2 & 25,5 & 31,8 & 20,7 & 13,9 & 6,8 & 4,13 \\
\hline M adeira e mobiliário & 1,6 & 49,7 & 30,0 & 13,5 & 4,1 & 1,0 & 2,50 \\
\hline Material de transporte & 1,0 & 7,2 & 16,8 & 35,7 & 29,4 & 9,9 & 5,58 \\
\hline M ecânica & 1,6 & 16,0 & 26,1 & 28,4 & 19,5 & 8,5 & 4,82 \\
\hline M etalúrgica & 1,4 & 22,2 & 29,9 & 27,4 & 15,3 & 3,9 & 3,88 \\
\hline M ineral não metálica & 2,0 & 51,2 & 26,3 & 13,7 & 5,1 & 1,7 & 2,60 \\
\hline Papel e gráfica & 5,5 & 36,3 & 23,5 & 19,1 & 10,9 & 4,7 & 3,44 \\
\hline Q ú́mica & 1,4 & 33,0 & 26,5 & 17,3 & 11,5 & 10,4 & 4,57 \\
\hline Têxtil & 2,8 & 62,7 & 21,2 & 9,4 & 3,1 & 0,8 & 2,19 \\
\hline
\end{tabular}

Fonte: RAIS - Ministério do Trabalho e Emprego

Tabela 7 - Percentuais de trabalhadores por nível de escolaridade em cada setor industrial, em 2005.

\begin{tabular}{|c|c|c|c|c|c|c|c|c|c|}
\hline \multirow[b]{2}{*}{ Indústrias } & \multicolumn{9}{|c|}{ N ível de escolaridade } \\
\hline & A nalfabeto & $\begin{array}{l}4 \text { a série } \\
\text { incomp }\end{array}$ & $\begin{array}{c}4 \stackrel{\text { a série }}{\text { comp }} \\
\end{array}$ & $\begin{array}{l}\text { 8a série } \\
\text { incomp }\end{array}$ & $\begin{array}{l}\text { 8a série } \\
\text { comp }\end{array}$ & $\begin{array}{l}2 . \text { grau } \\
\text { incomp }\end{array}$ & $\begin{array}{l}20 \text { grau } \\
\text { comp }\end{array}$ & $\begin{array}{c}\text { Sup. } \\
\text { incomp }\end{array}$ & $\begin{array}{l}\text { Sup. } \\
\text { comp }\end{array}$ \\
\hline A limentos e bebidas & 0,5 & 5,5 & 9,1 & 25,8 & 19,2 & 10,9 & 21,4 & 3,9 & 3,6 \\
\hline Borracha, fumo e couro. & 0,4 & 4,8 & 10,6 & 25,8 & 17,0 & 10,4 & 22,2 & 5,2 & 3,7 \\
\hline Calçados & 0,3 & 4,2 & 13,0 & 35,5 & 18,1 & 12,7 & 13,2 & 2,4 & 0,7 \\
\hline Elétrica e de comunicaçöes & 0,0 & 0,8 & 1,8 & 8,9 & 17,5 & 12,2 & 41,9 & 9,0 & 7,8 \\
\hline M adeira e mobiliário & 0,5 & 3,8 & 9,5 & 25,7 & 22,0 & 12,6 & 20,2 & 3,8 & 1,8 \\
\hline Material de tansporte & 0,1 & 1,4 & 4,3 & 8,9 & 21,6 & 9,8 & 37,7 & 8,4 & 7,8 \\
\hline Mecânica & 0,2 & 2,1 & 3,7 & 13,9 & 17,6 & 12,7 & 33,3 & 9,2 & 7,3 \\
\hline M etalúrgica & 0,3 & 3,1 & 5,8 & 19,1 & 22,9 & 11,6 & 27,8 & 5,7 & 3,8 \\
\hline M ineral não metálica & 1,1 & 6,9 & 10,8 & 26,7 & 22,9 & 9,6 & 16,4 & 3,1 & 2,5 \\
\hline Papel e G ráfica & 0,2 & 1,6 & 3,5 & 11,9 & 19,9 & 14,9 & 32,7 & 8,5 & 6,9 \\
\hline Q uímica & 0,1 & 2,3 & 4,7 & 16,7 & 19,4 & 11,3 & 31,1 & 7,1 & 7,2 \\
\hline Têxtil & 0,2 & 2,4 & 5,5 & 21,0 & 26,4 & 14,3 & 25,2 & 3,2 & 1,7 \\
\hline
\end{tabular}

Fonte: RAIS - Ministério do Trabalho e Emprego 
Tabela 8 - Diferenças dos percentuais de trabalhadores por níveis de salários mínimos e de escolaridade nas indústrias de alimentos e bebidas e de borracha, fumo e couro no Rio Grande Sul. Percentual de trabalhadores em 2005 menos o percentual, em 1996, no respectivo nível.

\begin{tabular}{|c|c|c|c|c|c|c|c|c|c|c|c|c|c|c|}
\hline \multirow{3}{*}{ Escolaridade } & \multicolumn{7}{|c|}{ A limentos e bebidas } & \multicolumn{7}{|c|}{ Borracha, fumo e couro } \\
\hline & \multicolumn{7}{|c|}{ Nivel salarial } & \multicolumn{7}{|c|}{ Nível salarial } \\
\hline & $\begin{array}{l}\text { A té } \\
1,0\end{array}$ & $\begin{array}{c}1,01 \mathrm{a} \\
2\end{array}$ & $\begin{array}{c}2,01 \mathrm{a} \\
3\end{array}$ & $\begin{array}{c}3,01 a \\
5\end{array}$ & $\begin{array}{c}5,01 \mathrm{a} \\
10 \\
\end{array}$ & $\begin{array}{l}\text { Mais } \\
\text { de } 10\end{array}$ & Total & $\begin{array}{l}\text { A té } \\
1,0\end{array}$ & $\begin{array}{c}1,01 \mathrm{a} \\
2\end{array}$ & $\begin{array}{c}2,01 \mathrm{a} \\
3\end{array}$ & $\begin{array}{c}3,01 \mathrm{a} \\
5\end{array}$ & $\begin{array}{c}5,01 \mathrm{a} \\
10\end{array}$ & $\begin{array}{l}\text { Mais } \\
\text { de } 10\end{array}$ & Total \\
\hline A nalfabeto & 0 & 0 & -1 & -1 & 0 & 0 & -2 & 0 & 0 & 0 & 0 & 0 & 0 & -1 \\
\hline 4 a série incomp & 0 & 0 & -3 & -3 & -1 & 0 & -8 & 0 & -3 & -4 & -3 & -1 & 0 & -10 \\
\hline 4 a série comp & 0 & 0 & -5 & -7 & -2 & 0 & -14 & 0 & -1 & -3 & -3 & -2 & -1 & -9 \\
\hline 8 a série incomp & 0 & 9 & -2 & -6 & -3 & -1 & -2 & 0 & 5 & -2 & -3 & -3 & -1 & -4 \\
\hline 8 a série comp & 0 & 8 & 1 & -1 & -1 & -1 & 6 & 0 & 6 & 0 & -1 & -2 & -1 & 2 \\
\hline 20 grau incomp & 0 & 5 & 1 & -1 & -1 & 0 & 4 & 0 & 4 & 0 & 0 & -1 & 0 & 3 \\
\hline 20 grau comp & 0 & 9 & 4 & 1 & -1 & -1 & 13 & 0 & 7 & 4 & 2 & 2 & -1 & 14 \\
\hline Super incomp & 0 & 1 & 1 & 1 & 0 & 0 & 2 & 0 & 1 & 1 & 1 & 1 & 0 & 3 \\
\hline Super comp & 0 & 0 & 0 & 1 & 1 & 0 & 1 & 0 & 0 & 0 & 0 & 1 & 0 & 2 \\
\hline Total & 1 & 32 & -3 & -17 & -9 & -4 & 0 & 0 & 19 & -4 & -6 & -5 & -4 & 0 \\
\hline
\end{tabular}

Fonte: RAIS - Ministério do Trabalho e Emprego.

Tabela 9 - Diferenças dos percentuais de trabalhadores por níveis de salários mínimos e de escolaridade nas indústrias de calçados e elétrica e de comunicação no Rio Grande Sul. Percentual de trabalhadores em 2005 menos o percentual, em 1996, no respectivo nível.

\begin{tabular}{|c|c|c|c|c|c|c|c|c|c|c|c|c|c|c|}
\hline \multirow{3}{*}{ Escolaridade } & \multicolumn{7}{|c|}{ Calçados } & \multicolumn{7}{|c|}{ Elétrica e de comunicação } \\
\hline & \multicolumn{7}{|c|}{ Nível salarial } & \multicolumn{7}{|c|}{ N ível salarial } \\
\hline & $\begin{array}{l}\text { A té } \\
1,0\end{array}$ & $\begin{array}{c}1,01 \mathrm{a} \\
2\end{array}$ & $\begin{array}{c}2,01 \mathrm{a} \\
3\end{array}$ & $\begin{array}{c}3,01 \mathrm{a} \\
5\end{array}$ & $\begin{array}{c}5,01 \mathrm{a} \\
10 \\
\end{array}$ & $\begin{array}{l}\text { Mais } \\
\text { de } 10\end{array}$ & Total & $\begin{array}{l}\text { A té } \\
1,0\end{array}$ & $\begin{array}{c}1,01 \mathrm{a} \\
2\end{array}$ & $\begin{array}{c}2,01 \mathrm{a} \\
3\end{array}$ & \begin{tabular}{|c}
$3,01 \mathrm{a}$ \\
5
\end{tabular} & $\begin{array}{c}5,01 \mathrm{a} \\
10\end{array}$ & $\begin{array}{l}\text { Mais } \\
\text { de } 10\end{array}$ & Total \\
\hline A nalfabeto & 0 & 0 & 0 & 0 & 0 & 0 & -1 & 0 & 0 & 0 & 0 & 0 & 0 & -1 \\
\hline $4 \stackrel{a}{a}$ série incomp & 0 & -1 & -4 & -4 & 0 & 0 & -9 & 0 & 0 & -2 & -2 & -1 & 0 & -6 \\
\hline 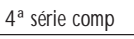 & 0 & -2 & -9 & -3 & -1 & 0 & -16 & 0 & 0 & -2 & -5 & -3 & -1 & -10 \\
\hline 8 a série incomp & 0 & 11 & -10 & -2 & -1 & 0 & -3 & 0 & 1 & -5 & -7 & -5 & -2 & -18 \\
\hline 8a série comp & 0 & 9 & 0 & 0 & 0 & 0 & 9 & 0 & 4 & 2 & -2 & -3 & -2 & 0 \\
\hline 20 grau incomp & 0 & 8 & 0 & 0 & 0 & 0 & 8 & 0 & 4 & 1 & -2 & -1 & -1 & 2 \\
\hline 20 grau comp & 0 & 7 & 2 & 1 & 0 & 0 & 10 & 0 & 10 & 13 & 5 & 0 & -1 & 27 \\
\hline Super incomp & 0 & 1 & 0 & 0 & 0 & 0 & 1 & 0 & 1 & 1 & 1 & 1 & -1 & 4 \\
\hline Super comp & 0 & 0 & 0 & 0 & 0 & 0 & 0 & 0 & 0 & 0 & 1 & 2 & 1 & 3 \\
\hline Total & 0 & 33 & -22 & -8 & -2 & -1 & 0 & 0 & 19 & 9 & -10 & -11 & -7 & 0 \\
\hline
\end{tabular}

Fonte: RAIS - Ministério do Trabalho e Emprego. 
Tabela 10 - Diferenças dos percentuais de trabalhadores por níveis de salários mínimos e de escolaridade nas indústrias de madeira e mobiliário e de material de transportes no Rio Grande Sul. Percentual de trabalhadores, em 2005, menos o percentual, em 1996, no respectivo nível.

\begin{tabular}{|c|c|c|c|c|c|c|c|c|c|c|c|c|c|c|}
\hline \multirow{3}{*}{ Escolaridade } & \multicolumn{7}{|c|}{ Madeira e mobiliário } & \multicolumn{7}{|c|}{ Material de transporte } \\
\hline & \multicolumn{7}{|c|}{ N ível salarial } & \multicolumn{7}{|c|}{ Nível salarial } \\
\hline & $\begin{array}{l}\text { A té } \\
1,0\end{array}$ & $\begin{array}{c}1,01 \mathrm{a} \\
2\end{array}$ & \begin{tabular}{|c|}
$2,01 a$ \\
3
\end{tabular} & $\begin{array}{c}3,01 \mathrm{a} \\
5\end{array}$ & $\begin{array}{c}5,01 \mathrm{a} \\
10\end{array}$ & $\begin{array}{l}\text { Mais } \\
\text { de } 10\end{array}$ & Total & $\begin{array}{l}\text { A té } \\
1,0\end{array}$ & $\begin{array}{c}1,01 \mathrm{a} \\
2\end{array}$ & $\begin{array}{c}2,01 \mathrm{a} \\
3\end{array}$ & $\begin{array}{c}3,01 \mathrm{a} \\
5\end{array}$ & $\begin{array}{c}5,01 \mathrm{a} \\
10\end{array}$ & $\begin{array}{l}\text { Mais } \\
\text { de } 10\end{array}$ & Total \\
\hline A nalfabeto & 0 & 0 & 0 & 0 & 0 & 0 & -1 & 0 & 0 & 0 & 0 & 0 & 0 & -1 \\
\hline 4 a série incomp & 0 & -1 & -2 & -1 & 0 & 0 & -4 & 0 & 0 & 0 & -1 & -2 & -1 & -4 \\
\hline 4 a série comp & 0 & -1 & -3 & -3 & -1 & 0 & -9 & 0 & 0 & -1 & -1 & -3 & -1 & -6 \\
\hline $8^{\text {a }}$ série incomp & 0 & 2 & -4 & -6 & -3 & 0 & -11 & 0 & 0 & -1 & -5 & -15 & -2 & -23 \\
\hline 8 a série comp & 0 & 5 & 1 & -1 & -1 & 0 & 3 & 0 & 0 & 2 & 5 & -1 & -1 & 5 \\
\hline 20 grau incomp & 0 & 4 & 1 & 0 & 0 & 0 & 5 & 0 & 1 & 1 & 1 & -3 & -1 & -1 \\
\hline $2 \stackrel{0}{\text { grau comp }}$ & 0 & 8 & 5 & 2 & 0 & 0 & 15 & 0 & 2 & 7 & 12 & 3 & -2 & 23 \\
\hline Super incomp & 0 & 1 & 1 & 1 & 0 & 0 & 2 & 0 & 0 & 1 & 2 & 1 & -1 & 3 \\
\hline Super comp & 0 & 0 & 0 & 0 & 0 & 0 & 1 & 0 & 0 & 0 & 1 & 1 & 1 & 3 \\
\hline Total & -1 & 18 & -1 & -10 & -6 & -2 & 0 & 0 & 4 & 8 & 14 & -18 & -8 & 0 \\
\hline
\end{tabular}

Fonte: RAIS - Ministério do Trabalho e Emprego.

Tabela 11 - Diferenças dos percentuais de trabalhadores por níveis de salários mínimose de escolaridade nas indústrias mecânica e metalúrgica no Rio Grande Sul. Percentual de trabalhadores, em 2005, menos o percentual, em 1996, no respectivo nível.

\begin{tabular}{|c|c|c|c|c|c|c|c|c|c|c|c|c|c|c|}
\hline \multirow{3}{*}{ Escolaridade } & \multicolumn{7}{|c|}{ M ecânica } & \multicolumn{7}{|c|}{ M etalúrgica } \\
\hline & \multicolumn{7}{|c|}{ N ível salarial } & \multicolumn{7}{|c|}{ N ível salarial } \\
\hline & $\begin{array}{l}\text { A té } \\
1,0\end{array}$ & $\begin{array}{c}1,01 \mathrm{a} \\
2\end{array}$ & \begin{tabular}{|c|}
$2,01 \mathrm{a}$ \\
3 \\
\end{tabular} & \begin{tabular}{|c|}
$3,01 \mathrm{a}$ \\
5 \\
\end{tabular} & $\begin{array}{c}5,01 \mathrm{a} \\
10 \\
\end{array}$ & $\begin{array}{l}\text { Mais } \\
\text { de } 10\end{array}$ & Total & $\begin{array}{l}\text { A té } \\
1,0\end{array}$ & $\begin{array}{c}1,01 \mathrm{a} \\
2\end{array}$ & $\begin{array}{c}2,01 \mathrm{a} \\
3\end{array}$ & \begin{tabular}{|c|}
$3,01 \mathrm{a}$ \\
5
\end{tabular} & $\begin{array}{c}5,01 \mathrm{a} \\
10\end{array}$ & $\begin{array}{l}\text { Mais } \\
\text { de } 10\end{array}$ & Total \\
\hline A nalfabeto & 0 & 0 & 0 & 0 & 0 & 0 & -1 & 0 & 0 & 0 & -1 & 0 & 0 & -1 \\
\hline 4 a série incomp & 0 & 0 & -1 & -2 & -2 & 0 & -5 & 0 & 0 & -2 & -3 & -2 & 0 & -7 \\
\hline 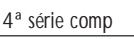 & 0 & 0 & -2 & -3 & -3 & -1 & -9 & 0 & 0 & -2 & -4 & -3 & -1 & -10 \\
\hline 8a série incomp & 0 & 1 & -2 & -6 & -7 & -2 & -16 & 0 & 2 & -2 & -5 & -5 & -1 & -12 \\
\hline 8a série comp & 0 & 2 & 2 & 0 & -3 & -2 & 0 & 0 & 4 & 3 & 1 & -2 & -1 & 5 \\
\hline 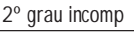 & 1 & 2 & 2 & 0 & -2 & -1 & 2 & 0 & 3 & 2 & 0 & -1 & -1 & 3 \\
\hline 2ㅇgrau comp & 0 & 5 & 7 & 7 & 2 & -1 & 21 & 0 & 5 & 6 & 6 & 2 & -1 & 19 \\
\hline Super incomp & 0 & 1 & 1 & 2 & 1 & -1 & 4 & 0 & 1 & 1 & 1 & 0 & -1 & 2 \\
\hline Super comp & 0 & 0 & 0 & 0 & 1 & 1 & 3 & 0 & 0 & 0 & 0 & 1 & 0 & 1 \\
\hline Total & 1 & 11 & 7 & -2 & -11 & -6 & 0 & 0 & 14 & 7 & -5 & -11 & -5 & 0 \\
\hline
\end{tabular}

Fonte: RAIS - Ministério do Trabalho e Emprego. 
Tabela 12 - Diferenças dos percentuais de trabalhadores por níveis de salários mínimose de escolaridade nas indústrias Mineral não metálica e Papel e Gráfica no Rio Grande Sul. Percentual de trabalhadores, em 2005, menos o percentual, em 1996, no respectivo nível.

\begin{tabular}{|c|c|c|c|c|c|c|c|c|c|c|c|c|c|c|}
\hline \multirow{3}{*}{ Escolaridade } & \multicolumn{7}{|c|}{ M ineral não metálica } & \multicolumn{7}{|c|}{ Papel e gráfica } \\
\hline & \multicolumn{7}{|c|}{ N ível salarial } & \multicolumn{7}{|c|}{$\mathrm{N}$ ível salarial } \\
\hline & $\begin{array}{l}\text { A té } \\
1,0\end{array}$ & $\begin{array}{c}1,01 \mathrm{a} \\
2\end{array}$ & $\begin{array}{c}2,01 \mathrm{a} \\
3\end{array}$ & $\begin{array}{c}3,01 \mathrm{a} \\
5\end{array}$ & $\begin{array}{c}5,01 \mathrm{a} \\
10\end{array}$ & $\begin{array}{l}\text { Mais } \\
\text { de } 10\end{array}$ & Total & $\begin{array}{l}\text { A té } \\
1,0\end{array}$ & $\begin{array}{c}1,01 \mathrm{a} \\
2\end{array}$ & $\begin{array}{c}2,01 \mathrm{a} \\
3\end{array}$ & $\begin{array}{c}3,01 \mathrm{a} \\
5\end{array}$ & $\begin{array}{c}5,01 \mathrm{a} \\
10\end{array}$ & $\begin{array}{l}\text { Mais } \\
\text { de } 10\end{array}$ & Tota \\
\hline A nalfabeto & 0 & 0 & 0 & -1 & 0 & 0 & -2 & 0 & 0 & 0 & 0 & 0 & 0 & -1 \\
\hline 4a série incomp & 0 & -1 & -2 & -2 & -1 & 0 & -7 & 0 & 0 & -1 & -1 & -1 & 0 & -3 \\
\hline 4 a série comp & 0 & -3 & -4 & -5 & -3 & 0 & -16 & 0 & -1 & -2 & -2 & -2 & -1 & -8 \\
\hline 8 a série incomp & 0 & 5 & -1 & -4 & -3 & 0 & -3 & -1 & 2 & -4 & -4 & -3 & -2 & -13 \\
\hline $8^{a}$ série comp & 0 & 8 & 3 & 0 & -1 & 0 & 9 & 2 & 4 & 0 & -2 & -2 & -2 & -1 \\
\hline 20 grau incomp & 0 & 4 & 1 & 0 & 0 & 0 & 5 & 1 & 4 & 1 & -1 & -2 & -1 & 3 \\
\hline 29 grau comp & 0 & 6 & 3 & 2 & 0 & 0 & 11 & 0 & 10 & 6 & 3 & 0 & 0 & 18 \\
\hline Super incomp & 0 & 1 & 1 & 0 & 0 & 0 & 1 & 0 & 2 & 1 & 1 & 0 & -1 & 3 \\
\hline Super comp & 0 & 0 & 0 & 0 & 0 & 0 & 1 & 0 & 0 & 0 & 2 & 0 & -1 & 2 \\
\hline Total & -1 & 21 & 1 & -9 & -9 & -3 & 0 & 2 & 20 & 0 & -6 & -10 & -7 & 0 \\
\hline
\end{tabular}

Fonte: RAIS - Ministério do Trabalho e Emprego.

Tabela 13 - Diferenças dos percentuais de trabalhadores por níveis de salários mínimos e de escolaridade nas indústrias Química e Têxtil no Rio Grande Sul. Percentual de trabalhadores, em 2005, menos o percentual, em 1996, no respectivo nível.

\begin{tabular}{|c|c|c|c|c|c|c|c|c|c|c|c|c|c|c|}
\hline \multirow{3}{*}{ Escolaridade } & \multicolumn{7}{|c|}{$Q$ uímica } & \multicolumn{7}{|c|}{ Textil } \\
\hline & \multicolumn{7}{|c|}{$\mathrm{N}$ ível salarial } & \multicolumn{7}{|c|}{ Nivel salarial } \\
\hline & $\begin{array}{l}\text { A té } \\
1,0\end{array}$ & $\begin{array}{c}1,01 \mathrm{a} \\
2\end{array}$ & $\begin{array}{c}2,01 \mathrm{a} \\
3\end{array}$ & $\begin{array}{c}3,01 \mathrm{a} \\
5\end{array}$ & $\begin{array}{c}5,01 \mathrm{a} \\
10\end{array}$ & $\begin{array}{l}\text { Mais } \\
\text { de } 10\end{array}$ & Total & $\begin{array}{l}\text { A té } \\
1,0\end{array}$ & $\begin{array}{c}1,01 \mathrm{a} \\
2\end{array}$ & $\begin{array}{c}2,01 \mathrm{a} \\
3\end{array}$ & $\begin{array}{c}3,01 \mathrm{a} \\
5\end{array}$ & $\begin{array}{c}5,01 \mathrm{a} \\
10\end{array}$ & $\begin{array}{l}\text { Mais } \\
\text { de } 10\end{array}$ & Total \\
\hline A nalfabeto & 0 & 0 & 0 & 0 & 0 & 0 & -1 & 0 & 0 & 0 & 0 & 0 & 0 & -1 \\
\hline $4^{\stackrel{a}{a} \text { série incomp }}$ & 0 & -1 & -1 & -1 & -1 & 0 & -4 & 0 & 0 & -1 & -1 & 0 & 0 & -3 \\
\hline $4 \stackrel{a}{a}$ série comp & 0 & -1 & -3 & -3 & -2 & -1 & -8 & 0 & -2 & -3 & -2 & -1 & 0 & -8 \\
\hline 8 a série incomp & 0 & 1 & -5 & -5 & -3 & -1 & -13 & -1 & 1 & -6 & -5 & -2 & 0 & -14 \\
\hline $8^{a}$ série comp & 0 & 5 & 1 & -1 & -2 & -2 & 2 & 0 & 9 & -2 & -2 & -1 & 0 & 3 \\
\hline 20 grau incomp & 0 & 3 & 1 & -1 & -1 & -1 & 3 & 0 & 6 & 0 & -1 & -1 & 0 & 4 \\
\hline 20 grau comp & 0 & 8 & 6 & 4 & 1 & -1 & 18 & 0 & 14 & 3 & 1 & -1 & 0 & 16 \\
\hline Super incomp & 0 & 1 & 1 & 1 & 0 & -1 & 2 & 0 & 1 & 1 & 0 & 0 & 0 & 1 \\
\hline Super comp & 0 & 0 & 0 & 1 & 1 & 0 & 2 & 0 & 0 & 0 & 0 & 0 & 0 & 0 \\
\hline Total & 1 & 18 & 0 & -6 & -6 & -6 & 0 & -1 & 29 & -10 & -10 & -5 & -2 & 0 \\
\hline
\end{tabular}

Fonte: RAIS - Ministério do Trabalho e Emprego. 